\title{
Changes in quadriceps muscle girth after anterior cruciate ligament injury followed by electrostimulation combined with high protein diet and exercises (ARPwave method)
}

\author{
doi: https://doi.org/10.5114/pq.2018.74703
}

\author{
Alicja Dziuba-Słonina, Aleksandra Rywacka, Małgorzata Kołodziej \\ University School of Physical Education in Wrocław, Wrocław, Poland
}

Abstract

Introduction. The aim of the study was to evaluate the clinical effectiveness of neuromuscular electrical stimulation (NMES) ARPwave in patients after knee joint injury.

Methods. The study involved 96 participants (66 men and 30 women). The ARPwave treatment consisted of 10 sessions of NMES combined with isometric and dynamic exercises and high protein diet. The girth of the left and right thigh was measured with an anthropometric measuring tape before and after the ARPwave therapy. Statistical analysis was carried out with the Statistca 12.5 software package.

Results. The differences observed between the results obtained for both limbs were statistically significant $(p<0.05)$ and did not depend on the type of injury or the applied rehabilitation $(p>0.05)$. However, significant differences in thigh girth were noted between sexes in the first and second measurement. The changes did not correlate with the sexes and were similar for both groups.

Conclusions. The results of the second measurement were significantly higher for all the variables. The mean changes were positive, which may indicate improvement of the patients' condition.

Key words: isometric and dynamic exercises, anthropometric measuring, muscle girth

\section{Introduction}

Soft tissue injuries of the knee joint are among the most common disorders. They often result from doing sports such as football, basketball, winter sports etc. Elderly and physically inactive people may also suffer from injuries. These are often caused by tearing the front anterior cruciate ligament (ACL), which makes it considerably more difficult or impossible to stay physically active or even walk [1-4]. Regaining strength of the quadriceps femoris muscle after such an injury is a huge challenge for patients and therapists. Attenuation of the muscle strength can last long after the rehabilitation process is completed [5]. The quadriceps muscle weakness after an ACL injury can be 15-40\% still even 14 years after the surgery [3]. There is a correlation between the quadriceps strength and limited knee joint mobility in the sagittal plane [1]. Research confirms that neuromuscular electrical stimulation (NMES) activates muscle strength and regaining the functions of the knee joint [6]. Thanks to modern technologies, electrostimulators are more frequently used in rehabilitation and have become user-friendly [6-8]. Changes after their application improve muscles performance and lower the risk of another injury. Therefore, they should be recommended by doctors [9]. A number of studies show that the NMES therapy should supplement physical exercises [2, 10].

Risberg et al. [4], in a review paper, presented the results of the effectiveness of 33 selected rehabilitation programs consisting of physical exercise and electrostimulation, carried out in years 1986-2001 after surgical intervention in the
ACL and without such intervention. The research confirms that rehabilitation should be implemented as soon as possible after ACL injury and that high-intensity NMES increases the quadriceps muscle strength [11], torque [12], and the kinematics parameters in walk analysis [13], as well as thigh girths [14].

Other publications prove the influence of high protein diet on gaining muscle mass $[15,16]$.

An idea to combine high protein diet with NMES was based on these findings. Accelerated Recovery Performance (ARPwave) [17] is an innovative rehabilitation method created for American professional athletes who suffered from an injury. The ARP Rx100 electrostimulator and its protocol have been approved by the Food and Drug Administration (FDA) as a medical device and procedures. The ARPwave therapy has been used in Poland for 4 years. ARP Rx100 is registered in the Office for Registration of Medicinal Products, Medical Devices and Biocidal Products. The ARPwave rehabilitation combines neurostimulation with physical exercises and high protein diet. The device generates modulated current formed by two types of overlapping current: direct $500 \mathrm{~Hz}$ and alternating $10-100 \mathrm{kHz}$.

This study aimed to evaluate the change of quadriceps muscle girth in patients who suffered from an ACL injury and took part in 10 ARPwave rehabilitation treatments. The secondary purpose was to determine whether the patients' sex, type of injury, or previous rehabilitation influenced the therapy progress.

Correspondence address: Alicja Dziuba-Słonina, Department of Physiotherapy in Motor Organ Dysfunctions, University School of Physical Education in Wrocław, al. I.J. Paderewskiego 35, 51-612 Wrocław, Poland, e-mail: alicja.dziuba@awf.wroc.pl 


\section{Subjects and methods}

\section{Participants}

The study involved 96 persons after an ACL injury. The group characteristics are shown in Table 1. The participants were inactive people (they did not do professional sports).

The youngest participant was 22 , while the oldest 55 years old. All the individuals were informed about the aim and methodology of the experiment. The total of 66 men and 30 women were tested; 31 (including 11 women) were after an ACL tear only, 29 (including 9 women) were after an ACL reconstruction only, 36 (including 9 women) were after an ACL injury together with a lateral collateral ligament (LCL) injury and/or medial collateral ligament (MCL) injury. Some patients (52 people) had been subject to traditional therapy before ARPwave. The rest of the participants (44 people) had not applied any kind of therapy. During the ARPwave therapy, the patients did not undergo any other type of therapy. ARPwave treatment was applied for both the healthy and the injured limb. With this in mind, the injured limb was categorized as the research group and healthy limb as the control group. The study and rehabilitation were conducted in a rehabilitation clinic in Wrocław.

\section{Experiment}

The ARPwave treatment consisted of 10 sessions combined with exercises and high protein diet. The therapy was conducted 5 times a week (excluding Saturday and Sunday). Each treatment took 30-40 minutes, the patient was prepared for 10 minutes (conversation and electrodes placement), the electrostimulation lasted for 30 minutes.

\section{Exclusion criteria}

These included: other movement injuries (i.e. lower limbs bruises, sprains, dislocations, and fractures within the 6 weeks prior to the first electrostimulation), injury to a joint different than knee, early post-operative stage (10 days after the surgery), deep venous thrombosis, pacemaker, pregnancy, cancer.

\section{Diet}

Before the treatment, the patients had received a list of high-protein foods and information on their protein content. Pure protein intake during the treatment was $0.7 \mathrm{~g} / \mathrm{kg} /$ day per patient.

\section{Electrostimulation}

At the beginning of the therapy, a portable electrode was used to locate the disorder of neuromuscular transmission. Two electrodes of the first circuit were placed on the skin over the targeted muscle. Additional two electrodes of

Table 1. Characteristics of the researched group

\begin{tabular}{|l|c|c|c|}
\hline Patients & $\begin{array}{c}\text { Age } \pm S D \\
\text { (years) }\end{array}$ & $\begin{array}{c}\text { Body height } \\
\pm S D(\mathrm{~cm})\end{array}$ & $\begin{array}{c}\text { Body mass } \\
\pm S D(\mathrm{~kg})\end{array}$ \\
\hline $\mathrm{F}+\mathrm{M}(n=96)$ & $36.5 \pm 13.4$ & $177.9 \pm 7.5$ & $76.2 \pm 12.5$ \\
\hline $\mathrm{F}(n=30)$ & $38.1 \pm 14.1$ & $172.4 \pm 8.7$ & $67.0 \pm 11.9$ \\
\hline $\mathrm{M}(n=66)$ & $35.8 \pm 12.9$ & $180.5 \pm 5.1$ & $80.6 \pm 10.0$ \\
\hline
\end{tabular}

the second circuit were applied in parallel, to the skin of the healthy limb. The therapy is always symmetrical. The injured extremity follows the movement pattern of the healthy one. There were 52 patients with the left limb healthy and 44 with the right one healthy.

\section{Kinesiotherapy}

The patients performed simple repeatable activity during electrical stimulation. Dynamic (concentric and eccentric) sit/stand exercises were performed from the $1^{\text {st }}$ to $4^{\text {th }}$ session - standing up and sitting down on a chair. The feet were positioned in parallel, $25-30 \mathrm{~cm}$ apart, and the knee joints bent from 0 to $90^{\circ}$. The exercise was repeated $5-10$ times. Each patient was asked to repeat the task as many times as they could but not fewer than 5 and not more than 10 times. From the $5^{\text {th }}$ to $10^{\text {th }}$ session, the patients performed dynamic (concentric and eccentric) and static (isometric) exercises wall squat and extreme. The patient remained in this position for a minute. Then, they stood up and bent forward with straight up legs and tense quadriceps muscles for a minute. The exercise was repeated 5 times.

\section{Research}

An anthropometric tape measure was used to determine the girths of the left and right thigh. The patient stood in a relaxed position. The study was always performed by the same researcher. The measurements before the $1^{\text {st }}(\mathrm{P} 1)$ and after the $10^{\text {th }}$ session (P2) were taken in the following way [18]:

$-17-20 \mathrm{~cm}$ above the base of the patella (P1-20, P2-20); the measurement was taken in the thickest part of the thigh; $\mathrm{U} 1$ - first thigh measurement, the widest part of the side and front head of the quadriceps;

- 8-10 cm over the base of the patella (P1-10, P2-10); U2 - second thigh measurement, the widest part of the middle head of the quadriceps;

-13-15 cm under the top of the patella (P1-15, P2-15); measurement taken in the thickest part of shank; G1 - first shin.

\section{Statistical analysis}

Basic statistical analysis was carried out with the Statistca 12.5 software (StatSoft Polska). The normal distribution of the analysed variables was verified with the KolmogorovSmirnov test. The significance of intergroup differences was analysed with variance analysis for repeated measurements, the gender effect, type of injury, and impact of the type of rehabilitation on the results between the $1^{\text {st }}$ and $2^{\text {nd }}$ measurement. Differences between the healthy and injured limb in sex groups were tested with the Mann-Whitney $U$ test. The results were considered statistically significant at $p<0.05$.

\section{Ethical approval}

The research related to human use has been complied with all the relevant national regulations and institutional policies, has followed the tenets of the Declaration of Helsinki, and has been approved by the Senate Ethics Committee of the University School of Physical Education in Wrocław.

\section{Informed consent}

Informed consent has been obtained from all individuals included in this study. 


\section{Results}

The researched group was homogeneous regarding all parameters. Table 1 shows the characteristics of the participants. The initial and final muscle girth in points $\mathrm{P}-10, \mathrm{P}-15$, and P-20 are presented in Table 2. Table 4 includes the absolute change of the girths between the final and initial treatment. After the treatment, the relative values of the quadriceps muscle girth in women increased by $\mathrm{H}_{w} 20=0.89 \%$, $\mathrm{H}_{\mathrm{w}} 10=0.72 \%, \mathrm{H}_{\mathrm{w}} 15=1.82 \%$ for the healthy limb and $\mathrm{I}_{\mathrm{w}} 20=$ $3.49 \%, I_{w} 10=3.33 \%, I_{w} 15=1.26 \%$ for the injured limb. In men, the relative girth of the quadriceps muscle raised by $\mathrm{H}_{w} 20=$ $1.56 \%, H_{w} 10=1.62 \%, H_{w} 15=0.59 \%$ for the healthy limb and $\mathrm{I}_{w} 20=3.48 \%, \mathrm{I}_{w} 10=3.85 \%, \mathrm{I}_{w} 15=1.30 \%$ for the injured limb. It means that apart from the girth at $15 \mathrm{~cm}$ among women, the results of the same treatment revealed a significant increase in the quadriceps muscle girth in both limbs for men and women.

It has been stated (Table 2) that the differences between the results of the repeated measurements (dependable) for both limbs were statistically significant $(p<0.05)$ and did not depend on the type of injury or the applied rehabilitation $(p>$ 0.05) (Table 3).
Significant differences in thighs girths of women and men were observed in the results of the $1^{\text {st }}$ and $2^{\text {nd }}$ measurement. However, sex did not have any influence on the changes, which were similar in both groups. Higher values in the $1^{\text {st }}$ and $2^{\text {nd }}$ measurement were obtained by men. There were no statistically significant differences between the $1^{\text {st }}$ and $2^{\text {nd }}$ measurement (change of girths) for either men or women. That implies that the changes (increase, differences) for men and women were similar. The treatment increased the girths in both groups, but it could not be determined whether the values were higher for men or women. Similar changes indicated that the therapy had influenced both men and women.

For all variables, the results of the $2^{\text {nd }}$ measurement were significantly higher than those of the $1^{\text {st }}$ one - the mean changes were positive, which indicated improvement of the patients' condition.

The Mann-Whitney $U$ test showed that the changes of the results for $20 \mathrm{~cm}$ and $10 \mathrm{~cm}$ for the injured limb were significantly greater than those for the healthy limb in both sexes (Table 4, Figure 1).

Table 2. Results of the variance analysis for repeated measurements

\begin{tabular}{|c|c|c|c|c|c|c|c|c|c|}
\hline & & & & & & & & \\
\hline & & $\begin{array}{c}\mathrm{F}(n=30) \\
\bar{x} \pm S D\end{array}$ & $\begin{array}{c}\mathrm{M}(n=66) \\
\bar{x} \pm S D\end{array}$ & $F_{\mathrm{P} 2-\mathrm{P} 1}$ & $p$ & $F_{\text {sex }}$ & $p$ & $F_{\mathrm{P} 2-\mathrm{P} 1 * \mathrm{sex}}$ & $p$ \\
\hline \multirow{6}{*}{$\mathrm{H}$} & $\mathrm{P} 1-20(\mathrm{~cm})$ & $52.55 \pm 6.19$ & $55.73 \pm 4.73$ & \multirow{2}{*}{30.81} & \multirow{2}{*}{0.001} & \multirow{2}{*}{7.771} & \multirow{2}{*}{0.007} & \multirow{2}{*}{1.47} & \multirow{2}{*}{0.229} \\
\hline & $\mathrm{P} 2-20(\mathrm{~cm})$ & $53.02 \pm 6.17$ & $56.60 \pm 4.76$ & & & & & & \\
\hline & $\mathrm{P} 1-10(\mathrm{~cm})$ & $44.58 \pm 5.59$ & $48.23 \pm 5.21$ & \multirow{2}{*}{12.38} & \multirow{2}{*}{0.001} & \multirow{2}{*}{8.406} & \multirow{2}{*}{0.005} & \multirow{2}{*}{2.72} & \multirow{2}{*}{0.103} \\
\hline & $\mathrm{P} 2-10(\mathrm{~cm})$ & $44.90 \pm 5.64$ & $49.01 \pm 5.12$ & & & & & & \\
\hline & $\mathrm{P} 1-15$ (cm) & $35.8 \pm 4.41$ & $38.81 \pm 3.70$ & \multirow{2}{*}{4.77} & \multirow{2}{*}{0.032} & \multirow{2}{*}{9.336} & \multirow{2}{*}{0.003} & \multirow{2}{*}{1.13} & \multirow{2}{*}{0.290} \\
\hline & $\mathrm{P} 2-15(\mathrm{~cm})$ & $36.45 \pm 4.61$ & $39.04 \pm 3.75$ & & & & & & \\
\hline \multirow{6}{*}{ I } & $\mathrm{P} 1-20(\mathrm{~cm})$ & $50.67 \pm 5.74$ & $54.36 \pm 4.82$ & \multirow{2}{*}{140.62} & \multirow{2}{*}{$<0.001$} & \multirow{2}{*}{9.058} & \multirow{2}{*}{0.003} & \multirow{2}{*}{0.13} & \multirow{2}{*}{0.721} \\
\hline & $\mathrm{P} 2-20(\mathrm{~cm})$ & $52.43 \pm 6.05$ & $56.25 \pm 4.63$ & & & & & & \\
\hline & $\mathrm{P} 1-10(\mathrm{~cm})$ & $43.00 \pm 5.33$ & $46.76 \pm 5.08$ & \multirow{2}{*}{75.95} & \multirow{2}{*}{$<0.001$} & \multirow{2}{*}{8.272} & \multirow{2}{*}{0.005} & \multirow{2}{*}{0.82} & \multirow{2}{*}{0.369} \\
\hline & $\mathrm{P} 2-10(\mathrm{~cm})$ & $44.43 \pm 5.59$ & $48.55 \pm 5.15$ & & & & & & \\
\hline & $\mathrm{P} 1-15(\mathrm{~cm})$ & $35.60 \pm 4.15$ & $38.45 \pm 3.58$ & \multirow{2}{*}{7.76} & רחת & 5 & ? & 4 & 17 \\
\hline & $\mathrm{P} 2-15(\mathrm{~cm})$ & $36.05 \pm 4.19$ & $38.95 \pm 3.63$ & & 0.001 & 0.170 & 0.002 & 0.04 & 0.041 \\
\hline
\end{tabular}

$\mathrm{H}$ - healthy limb, I - injured limb, F - female, M - male, P1 - measurement of thigh girth before the therapy (in the described spots around the patella: $10 \mathrm{~cm}, 15 \mathrm{~cm}$, and $20 \mathrm{~cm}$ ), P2 - measurement of thigh girth after 10 therapy sessions (in the described spots around the patella: $10 \mathrm{~cm}, 15 \mathrm{~cm}$, and $20 \mathrm{~cm}$ ), $\bar{x}$ - mean, $S D$ - standard deviation, $F$ - Fisher's test value, $p$ - testing mistake probability

Table 3. Variance analysis for repeated measurements as related to the type of injury or the applied rehabilitation

\begin{tabular}{|l|c|c|c|c|c|c|}
\hline \multirow{2}{*}{ Parameter } & \multicolumn{2}{|c|}{$\mathrm{P} 2-\mathrm{P} 1=20 \mathrm{~cm}$} & \multicolumn{2}{c|}{$\mathrm{P} 2-\mathrm{P} 1=10 \mathrm{~cm}-\mathrm{P} 1=15 \mathrm{~cm}$} \\
\cline { 2 - 7 } & $F$ & $\mathrm{~F}$ & $\mathrm{~F}$ & $\mathrm{P}$ & $\mathrm{F}$ & $\mathrm{P}$ \\
\hline $\mathrm{I}$ & 0.523 & 0.5948 & 0.271 & 0.7636 & 0.738 & 0.4812 \\
\hline $\mathrm{R}$ & 1.090 & 0.2995 & 0.957 & 0.3306 & 2.769 & 0.0998 \\
\hline $\mathrm{S}{ }^{*} \mathrm{I}_{\mathrm{t}}$ & 1.663 & 0.1956 & 2.057 & 0.1341 & 1.716 & 0.1860 \\
\hline $\mathrm{S}{ }^{*} \mathrm{R}$ & 0.337 & 0.5633 & 0.147 & 0.7027 & 0.966 & 0.3284 \\
\hline $\mathrm{I}_{\mathrm{t}}{ }^{*} \mathrm{R}$ & 1.405 & 0.2510 & 0.814 & 0.4463 & 0.391 & 0.6775 \\
\hline $\mathrm{S}^{*} \mathrm{I}_{\mathrm{t}}{ }^{*} \mathrm{R}$ & 0.179 & 0.8365 & 0.449 & 0.6395 & 0.098 & 0.9067 \\
\hline
\end{tabular}

$\mathrm{I}_{\mathrm{t}}$ - type of injury, $\mathrm{R}$ - applied rehabilitation, $\mathrm{S}$ - sex, P1 - measurement of thigh girth before the therapy, $\mathrm{P} 2$ - measurement of thigh girth after 10 therapy sessions, $F$ - Fisher's test value, $p$ - testing mistake probability 
Table 4. Differences between mean changes in thigh girths of the healthy limb and of the injured limb

\begin{tabular}{|c|c|c|c|c|c|c|}
\hline & P2-P1 & $\begin{array}{c}\mathrm{H} \\
\bar{x} \pm S D\end{array}$ & $\begin{array}{c}\text { । } \\
\bar{x} \pm S D\end{array}$ & $U$ & $z$ & $p$ \\
\hline \multirow{3}{*}{$\mathrm{F}$} & $20(\mathrm{~cm})$ & $0.47 \pm 0.74$ & $1.77 \pm 0.95$ & 111.0 & -5.00 & $<0.001$ \\
\hline & $10(\mathrm{~cm})$ & $0.32 \pm 0.58$ & $1.43 \pm 0.89$ & 111.0 & -5.00 & $<0.001$ \\
\hline & $15(\mathrm{~cm})$ & $0.65 \pm 1.88$ & $0.45 \pm 0.78$ & 383.0 & -0.98 & 0.326 \\
\hline \multirow{3}{*}{ M } & $20(\mathrm{~cm})$ & $0.87 \pm 0.87$ & $1.89 \pm 1.07$ & 915.5 & -5.74 & $<0.001$ \\
\hline & $10(\mathrm{~cm})$ & $0.78 \pm 0.90$ & $1.80 \pm 1.31$ & 947.0 & -5.60 & $<0.001$ \\
\hline & $15(\mathrm{~cm})$ & $0.23 \pm 0.92$ & $0.50 \pm 1.02$ & 1844.0 & -1.52 & 0.129 \\
\hline
\end{tabular}

$\mathrm{F}$ - female, M - male, P1 - measurement of thigh girth before the therapy, P2 - measurement of thigh girth after 10 therapy sessions, $\mathrm{H}$ - healthy limb, I - injured limb, $\bar{x}-$ mean, $S D$ - standard deviation, $U$ - Mann-Whitney $\mathrm{U}$ test value, $Z$ - standard test value $\mathrm{U}$, $p$ - testing mistake probability $\mathrm{U}$
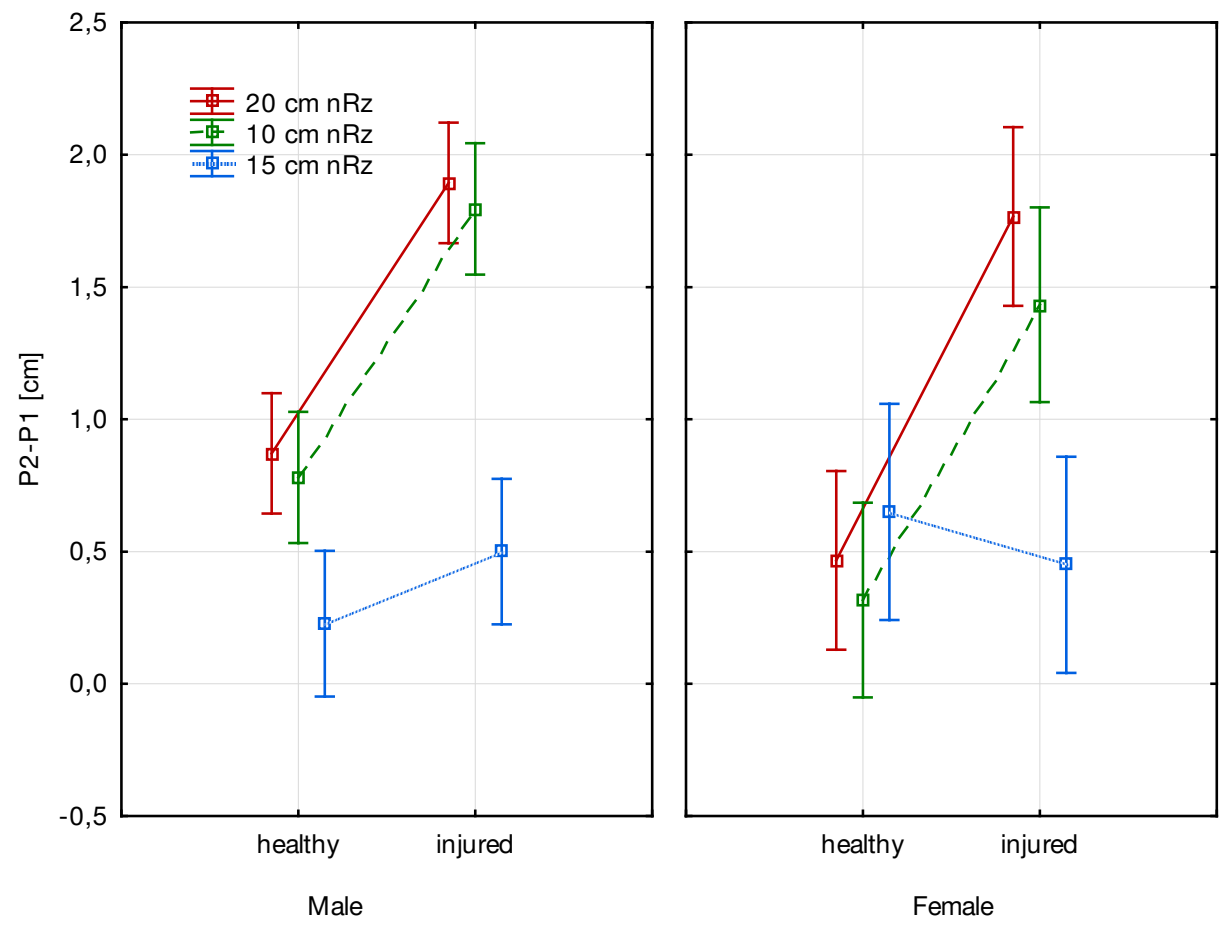

Figure 1. Differences between changes of quadriceps girths of the healthy limb and of the injured limb in both sex groups

\section{Discussion}

The conducted research has shown that the ARPwave method is effective in quadriceps muscle physiotherapy. The ARPwave method of the quadriceps muscle electrostimulation combined with high protein diet and kinesiotherapy increased thigh girth in the injured limb. There are many examples of using electrical current and exercises among sportspeople to increase their muscle mass and power. However, there are still few individuals willing to participate in studies. There is also little information about the influence of sex, additional rehabilitation, and ways of nutrition.

Taradaj et al. [2] investigated the influence of electrostimulation on muscle power among athletes after ACL reconstruction. They observed a $28.7 \%$ increase of the quadriceps muscle strength in the post-operation group which underwent electrostimulation therapy. In the control group (no electrostimulation), muscle strength increased only by $4.6 \%$. The authors also measured the girths of muscles in the group of sportspeople. In the injured limb, the girth increased by $1.4 \%$ in the electrostimulation group and by $0.6 \%$ in the control group. The results obtained in our research were similar, although the relative increase was higher. The girth of the injured limb increased by $3.48-3.85 \%$ in men and $0.72-0.89 \%$ in women. Our own study was based on a higher number (96) of individuals and analysed the influence of sex. High protein diet, used by the participants, may impact on a greater muscle increase. Longland et al. [16] tested the influence of a highprotein diet applied by athletes doing physical exercises on body composition and muscle torque. The participants also took part in aerobic and anaerobic testing, blood sampling, hormonal measurements, and urinary measures. The authors observed a statistically significant increase in lean body mass among physically active participants on an increased protein diet. The muscle torque raised in both groups (normal and increased protein diet) but the noted differences were not statistically significant. Most parameters measured in blood and urinary samples increased, and the changes were statistically significant for the group with the higher amount of protein in the diet.

Pasiakos et al. [15] stated that high-protein consumption, above the recommended dietary allowance (RDA), might maintain the fat-free mass during short term weight loss. They determined the influence of different levels of dietary protein 
on body composition and muscle protein synthesis during energy deficit (ED). The research included 39 adults. Their daily protein intake was 0.8 (RDA), 1.6 (2aRDA), and 2.4 (3aRDA) $\mathrm{g} / \mathrm{kg}$ for 31 days. After 10 days of weight maintenance (WM), there was 21-day ED. Body composition and protein synthesis were evaluated during WM (days 1-10) and ED (days 30-31). Loss of $(p<0.05) 3.2 \pm 0.2 \mathrm{~kg}$ during ED did not depend on the protein diet. Among the participants with 2aRDA and 3aRDA, the ratio of weight loss to fat-free mass was lower $(p<0.05)$ and the loss of fat mass turned out higher $(p<0.05)$ in comparison with RDA.

Stevens-Lapsey et al. [6] proved the influence of NMES current strength on the quadriceps muscle strength after total knee arthroplasty. Unfortunately, the research group comprised only 15 participants in the NMES group and 15 in the control group. The participants were 65 years old and were not divided into sex categories.

Fitzgerald et al. [11] investigated the influence of NMES in rehabilitation after $A C L$ reconstruction. The research and control groups comprised 20 participants each. Muscle strength increased after 12 and 16 weeks in the NMES group. Similar to our findings, sex had no influence on the result. However, too few patients participated in the study to confirm this hypothesis. The authors showed that the results were influenced by age, body height, body weight, level of physical activity, and time after the surgery.

Adams et al. [3] aimed to create an optimal criterion for rehabilitation treatment of patients after a knee joint injury. The literature review confirmed that NMES could be used to increase the quadriceps muscle mass and strengthen its activity. NMES recruits motor neurons, which produce greater quadriceps muscle strength than exercises.

Otzel et al. [14] studied the strength and girth of quadriceps muscles in people after ACL reconstruction. As in our study, the authors compared the values obtained for the healthy and injured limb. The participants performed isokinetic exercises. There were no differences in the thigh girth between the healthy and injured limb in the studied group; however, only 24 individuals were tested.

Previous studies have shown that eccentric exercises produce the best results in patients after ACL reconstruction. Thus, Lepley et al. [10] conducted research on 4 groups after ACL reconstruction. The first group underwent only NMES, the second one used NMES and eccentric exercises, the third one practised only eccentric exercises, and the fourth one applied only traditional therapy. The research showed that the best results - wide range of movement in the knee joint in the sagittal plane and higher torque - were observed in the group that combined NMES with eccentric exercises.

Kim et al. [19] analysed 301 random scientific studies using electronic databases from 1966 to October 2008. All of the studies tested the effectiveness of NMES and physical exercises in the rehabilitation of patients after an ACL injury. The results were based on 8 papers selected with the Physiotherapy Evidence Database Scale. The knee joint torque analysis proved that NMES combined with exercises might have a greater influence on the increase of the quadriceps muscle strength than exercises alone.

Filipovic et al. [20] also analysed the NMES effects on chosen endurance parameters in sportspeople. The selection of 89 out of 200 studies was performed in accordance with the following criteria: age (35 years), healthy patient, NMES type (skin stimulation). Then, the type of NMES (homotopic and whole body) and muscle contractions (isometric, dynamic, isokinetic) were used to determine the following parameters: maximum force, speed, power. After 3-6-week stimulation, significant increases $(p<0.05)$ were observed in the maximum force (isometric contraction Fmax $+58.8 \%$, dynamic Fmax $+79.5 \%$ ), torque (eccentric isokinetic Mmax $+41.3 \%$ ), and power (+67\%). The vertical jump height increased by $25 \%$ and the time of sprint improved by up to $-4.8 \%$.

In line with the previous studies, it can be stated that the ARPwave therapy has a positive influence on quadriceps mass increase in people who suffered from an ALC ligament injury. There are no studies in literature which analysed 96 participants and combined 3 factors: muscle electrostimulation, static and dynamic exercises, and high protein diet. It is worth emphasizing that we took into consideration the influence of sex, previous therapy, and the type of knee joint injury.

\section{Limitations}

The research should be continued; it would be worth expanding it by a bioelectrical impedance analysis (BIA), considered as one of the most reliable and non-invasive methods of determining body composition, and by the methodology of EMG treatment and muscle torque.

It is also advisable to perform a segment analysis of the muscle mass in order to control the amount of muscle mass of individual parts of the body. This would allow to check whether the implemented training plan expands all parts of the body in the same degree of rehabilitation effects.

\section{Conclusions}

The results of this experiment led to the conclusion that the ARPwave method, combining electrostimulation with static and dynamic exercises and high protein diet, was useful in enlarging quadriceps girth after a knee joint injury. The increases of the quadriceps girth were significantly higher after 10 sessions of ARPwave treatment in the injured limb as compared with the healthy one.

Such parameters as sex, type of previous rehabilitation, or type of injury had no influence on the change in the quadriceps girth.

\section{Disclosure statement}

No author has any financial interest or received any financial benefit from this research.

\section{Conflict of interest}

The authors state no conflict of interest.

\section{References}

1. Lewek M, Rudolph K, Axe M, Snyder-Mackler L. The effect of insufficient quadriceps strength on gait after anterior cruciate ligament reconstruction. Clin Biomech. 2002; 17(1):56-63; doi: 10.1016/S0268-0033(01)00097-3.

2. Taradaj J, Halski T, Kucharzewski M, Walewicz K, Smykla $A$, Ozon M, et al. The effect of neuromuscular electrical stimulation on quadriceps strength and knee function in professional soccer players: return to sport after ACLreconstruction. BiomedResInt.2013;2013:802534; doi: 10.1155/2013/802534.

3. Adams D, Logerstedt D, Hunter-Giordano A, Axe MJ, Snyder-Mackler L. Current concepts for anterior cruciate ligament reconstruction: a criterion-based rehabilitation progression. J Orthop Sports Phys Ther. 2012;42(7): 601-614; doi: 10.2519/jospt.2012.3871.

4. Risberg MA, Lewek M, Snyder-Mackler L. A systematic review of evidence for anterior cruciate ligament reha- 
bilitation: how much and what type? Phys Ther Sport. 2004;5(3):125-145; doi: 10.1016/j.ptsp.2004.02.003.

5. Tourville TW, Jarrell KM, Naud S, Slauterbeck JR, Johnson RJ, Beynnon BD. Relationship between isokinetic strength and tibiofemoral joint space width changes after anterior cruciate ligament reconstruction. Am J Sports Med.2014;42(2):302-311;doi:10.1177/0363546513510672.

6. Stevens-Lapsley JE, Balter JE, Wolfe P, Eckhoff DG, Kohrt WM. Early neuromuscular electrical stimulation to improve quadriceps muscle strength after total knee arthroplasty: a randomized controlled trial. Phys Ther. 2012;92(2):210-226; doi: 10.2522/ptj.20110124.

7. Walls RJ, McHugh G, O'Gorman DJ, Moyna NM, O'Byrne JM. Effects of preoperative neuromuscular electrical stimulation on quadriceps strength and functional recovery in total knee arthroplasty. A pilot study. BMC Musculoskelet Disord. 2010;11:119; doi: 10.1186/1471-247411-119.

8. Makles-Kacy I, Zys-Owczarek E, Polak A, Maciejewski A. Physiotherapy in the first three months after allograft face transplantation - case report. Physiotherapy Quarterly. 2016;24(1):34-38; doi: 10.1515/physio-2016-0006.

9. Oberländer KD, Brüggemann GP, Höher J, Karamanidis K. Altered landing mechanics in ACL-reconstructed patients. Med Sci Sports Exerc. 2013;45(3):506-513; doi: 10.1249/MSS.0b013e3182752ae3.

10. Lepley LK, Wojtys EM, Palmieri-Smith RM. Combination of eccentric exercise and neuromuscular electrical stimulation to improve biomechanical limb symmetry after anterior cruciate ligament reconstruction. Clin Biomech. 2015;30(7):738-747; doi: 10.1016/j.clinbiomech.2015.04.011.

11. Fitzgerald GK, Piva SR, Irrgang JJ. A modified neuromuscular electrical stimulation protocol for quadriceps strength training following anterior cruciate ligament reconstruction. J Orthop Sports Phys Ther. 2003;33(9): 492-501; doi: 10.2519/jospt.2003.33.9.492.

12. Liu-Ambrose T, Taunton JE, Maclntyre D, McConkey P, Khan KM. The effects of proprioceptive or strength training on the neuromuscular function of the ACL reconstructed knee: a randomized clinical trial. Scand J Med Sci Sports. 2003;13(2):115-123; doi: 10.1034/j.1600-0838. 2003.02113.x.

13. Hooper DM, Morrissey MC, Drechsler W, Morrissey D, King J. Open and closed kinetic chain exercises in the early period after anterior cruciate ligament reconstruction. Improvements in level walking, stair ascent, and stair descent. Am J Sports Med. 2001;29(2):167-174; doi: 10.1177/03635465010290020901.

14. Otzel DM, Chow JW, Tillman MD. Long-term deficits in quadriceps strength and activation following anterior cruciate ligament reconstruction. Phys Ther Sport. 2015;16(1):22-28; doi: 10.1016/j.ptsp.2014.02.003.

15. Pasiakos SM, Cao JJ, Margolis LM, Sauter ER, Whigham LD, McClung JP, et al. Effects of high-protein diets on fat-free mass and muscle protein synthesis following weight loss: a randomized controlled trial. FASEB J. 2013;27(9):3837-3847; doi: 10.1096/fj.13-230227.

16. Longland TM, Oikawa SY, Mitchell CJ, Devries MC, Phillips SM. Higher compared with lower dietary protein during an energy deficit combined with intense exercise promotes greater lean mass gain and fat mass loss: a randomized trial. Am J Clin Nutr. 2016;103(3):738-746; doi: 10.3945/ajcn.115.119339.

17. United States Patent and Trademark Office. 1978; appli-
18. Białoszewski D, Woźniak W, Zarek S. Clinical efficacy of kinesiology taping in reducing edema of the lower limbs in patients treated with the llizarov method - preliminary report. Ortop Traumatol Rehabil. 2009;11(1):46-54.

19. Kim KM, Croy T, Hertel J, Saliba S. Effects of neuromuscular electrical stimulation after anterior cruciate ligament reconstruction on quadriceps strength, function, and patient-oriented outcomes: a systematic review. J Orthop Sports Phys Ther. 2010;40(7):383-391; doi: 10.2519/ jospt.2010.3184.

20. Filipovic A, Kleinöder H, Dörmann U, Master J. Electromyostimulation - a systematic review of the effects of different electromyostimulation methods on selected strength parameters in trained and elite athletes. J Strength Cond Res. 2012;26(9):2600-2614; doi: 10.1519/JSC. 0b013e31823f2cd1. 